\title{
Inner structure of the Puy de Dôme volcano: cross-comparison of geophysical models (ERT, gravimetry, muon imaging)
}

\author{
A. Portal ${ }^{1,3,4}$, P. Labazuy ${ }^{1,3,4}$, J.-F. Lénat ${ }^{1,3,4}$, S. Béné ${ }^{2}$, P. Boivin ${ }^{1,3,4}$, E. Busato ${ }^{2}$, C. Cârloganu ${ }^{2}$, C. Combaret ${ }^{5}$, \\ P. Dupieux ${ }^{2}$, F. Fehr ${ }^{2}$, P. Gay ${ }^{2}$, I. Laktineh ${ }^{5}$, D. Miallier ${ }^{2}$, L. Mirabito ${ }^{5}$, V. Niess ${ }^{2}$, and B. Vulpescu ${ }^{2}$ \\ ${ }^{1}$ Clermont Université, Université Blaise Pascal, Observatoire de Physique du Globe de Clermont-Ferrand, \\ Laboratoire Magmas et Volcans, BP 10118, 63000 Clermont-Ferrand, France \\ ${ }^{2}$ Clermont Université, Université Blaise Pascal, CNRS/IN2P3, Laboratoire de Physique Corpusculaire, BP 10118, \\ 63000 Clermont-Ferrand, France \\ ${ }^{3}$ Centre National de la Recherche Scientifique - UMR6524, LMV, 63038 Clermont-Ferrand, France \\ ${ }^{4}$ Institut de Recherche pour le Développement, R 163, LMV, 63038 Clermont-Ferrand, France \\ ${ }^{5}$ Université de Lyon, Université Lyon 1, CNRS/IN2P3, IPNL, 1 Rue E. Fermi, 69622 Villeurbanne Cedex, France
}

Correspondence to: A. Portal (a.portal@opgc.univ-bpclermont.fr)

Received: 18 July 2012 - Published in Geosci. Instrum. Method. Data Syst. Discuss.: 5 September 2012

Revised: 18 December 2012 - Accepted: 26 December 2012 - Published: 28 January 2013

\begin{abstract}
Muon imaging of volcanoes and of geological structures in general is actively being developed by several groups in the world. It has the potential to provide 3-D density distributions with an accuracy of a few percent. At this stage of development, comparisons with established geophysical methods are useful to validate the method. An experiment has been carried out in 2011 and 2012 on a large trachytic dome, the Puy de Dôme volcano, to perform such a comparison of muon imaging with gravimetric tomography and 2-D electrical resistivity tomography. Here, we present the preliminary results for the last two methods.

North-south and east-west resistivity profiles allow us to model the resistivity distribution down to the base of the dome. The modelling of the Bouguer anomaly provides models for the density distribution within the dome that are directly comparable with the results from the muon imaging. Our ultimate goal is to derive a model of the dome using the joint interpretation of all sets of data.
\end{abstract}

\section{Introduction}

The Puy de Dôme is a 11000 -yr-old and 400-m-high trachytic dome located in the central part of the Chaîne des Puys volcanic field (Massif Central, France). Its morphology suggests the presence of two distinct units (Fig. 1), the second unit being situated in the scar of a sector collapse of the first unit (Boivin et al., 2009). The high-resolution $(50 \mathrm{~cm})$ topography from a LiDAR survey (Fig. 1) tends to support this structural model. The Puy de Dôme construction was accompanied and followed by significant fumarolic and hydrothermal activity, as shown by the hydrothermal alteration features on summit outcrops. A late phreatomagmatic eruption of weak amplitude marked the end of the dome activity (Miallier et al., 2010).

The ToMuVol (Muonic Tomography of Volcanoes) collaboration brings together geologists and volcanologists from LMV (Laboratoire Magmas et Volcans) and particle physicists from IPNL (Institut de Physique Nucléaire de Lyon) and LPC (Laboratoire de Physique Corpusculaire). The collaboration develops muon tomography for studying and monitoring volcanoes. At the origin of muon tomography, the muon radiography is an old technique applied as early as 1970 to the study of pyramid structure (Alvarez et al., 1970), and more recently applied to volcanoes (Nagamine, 1995; Nagamine et al., 1995). Radiographic measurements (Tanaka and Yokoyama, 2008; Tanaka et al., 2005, 2007, 2009a,b) and even a tomographic imaging (Tanaka et al., 2010) have already been carried out on small volcanoes in Japan. In addition, a recent study makes a first comparison of muon radiography results (Gibert et al., 2010; Marteau et al., 2012) 


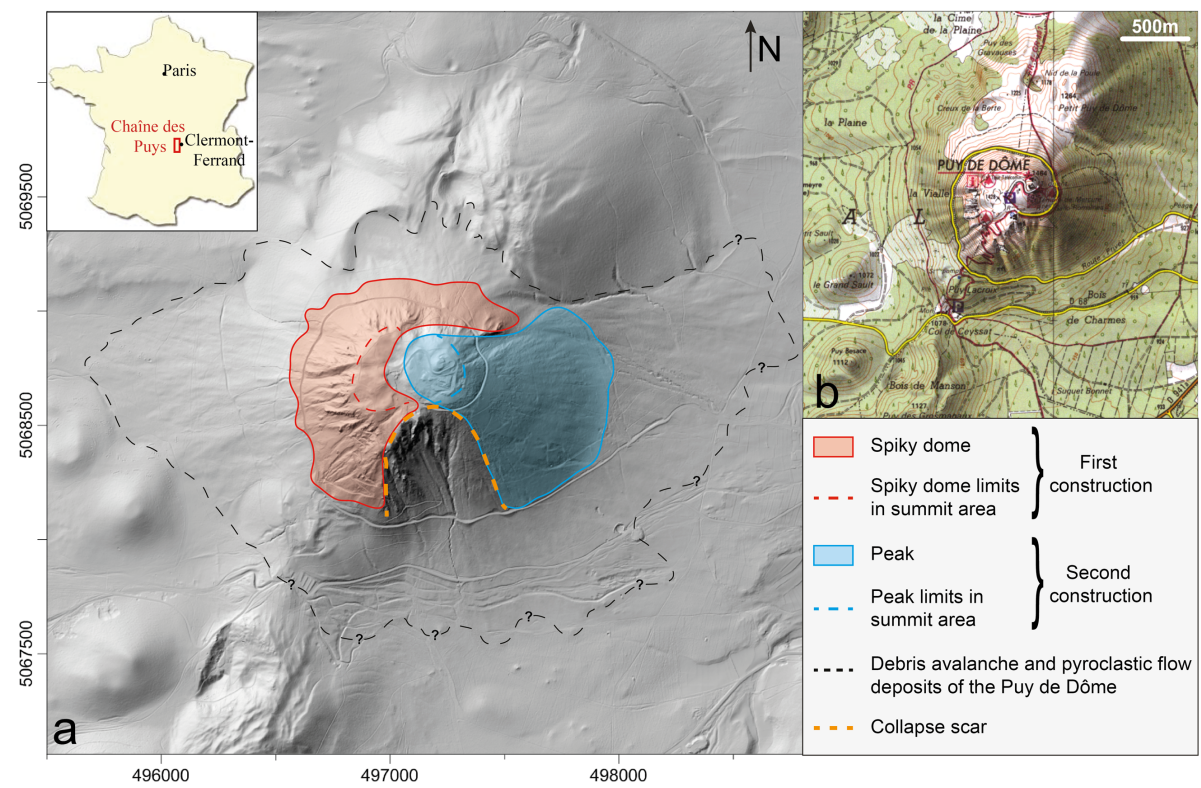

Fig. 1. (a) High-resolution LiDAR DTM of the Puy de Dôme $(50 \mathrm{~cm}$ resolution, CRAIG - GeoPhenix 2011, coordinates in meters WGS84, UTM31N). The two inferred constructional units of the volcano are identified: the first construction is a spiky dome to the west, whereas a peak forms the second construction and its deposits form very regular slopes at the east. A collapse scar is identified in the southern part of the dome. (b) Topographic map of the Puy de Dôme volcano.

with other geophysical data for la Soufrière de Guadeloupe volcano (Lesparre et al., 2012).

The Puy de Dôme was selected as an experimental site for the ToMuVol project, because, besides its accessibility and proximity to the laboratories in Clermont-Ferrand, it has ideal geological and morphological characteristics: it is a large target with simple external shape but likely complex internal structure. Radiographic measurements using atmospheric muons were performed in 2011 and 2012 from two different viewpoints (Cârloganu et al., 2012). Two geophysical surveys have been carried out on the Puy de Dôme: electrical resistivity tomography measurements (June 2011 and May 2012) and a high-resolution gravity survey (March and May 2012).

The objective of this work is to make a preliminary comparison of the structure models inferred from electrical and gravity measurements. Since a preliminary density distribution obtained through muon radiography in 2011 is available for the Puy de Dôme (Béné, 2012; Cârloganu et al., 2012), it can be compared with these geophysical models.

\section{Methodology}

\subsection{Electrical resistivity tomography (ERT)}

The ERT method provides images of the distribution of the electrical resistivity of the rocks at depth. In the case of the Puy de Dôme volcano, field measurements were made with a quadripole system. An electric current is injected through two electrodes, and the remaining two electrodes measure the potential difference created by this current in the middle of the line of electrodes (Marescot, 2004 and references therein). Since the electric field depends on the distribution of resistivity, the measurement of the injected current and of the potential difference allows the calculation of an apparent resistivity for different quadripole geometries. The resistivity distribution at depth is investigated by modelling.

The rock resistivity depends on the content and nature of the fluid (usually water), the permeability and the alteration of the rocks (presence of hydrated minerals). Geological interpretations of resistivity models can be ambiguous, because different lithologies can have similar resistivities and also because of the non-uniqueness of the calculated models. On the other hand, the resistivity of rocks within a structure such as the studied dome may vary significantly (a several orders of magnitude range is likely for the Puy de Dôme), and therefore the method has a high potential to differentiate volcanic structures.

Figure 2 shows the location of the electrical acquisition lines. We used an ABEM SAS 4000 system with 64 electrodes, with an electrode spacing of $5 \mathrm{~m}$ in the summit area and of $35 \mathrm{~m}$ on the flanks. The measurement protocols used were both Wenner, which has the best vertical sensibility, and Wenner-Schlumberger, which offers both vertical and horizontal sensibilities (White et al., 2003). For the eastern part of the west-east profile, we suspect that a connection default in the electric line may have perturbed the measurements, and therefore we do not use this segment of the data here. 


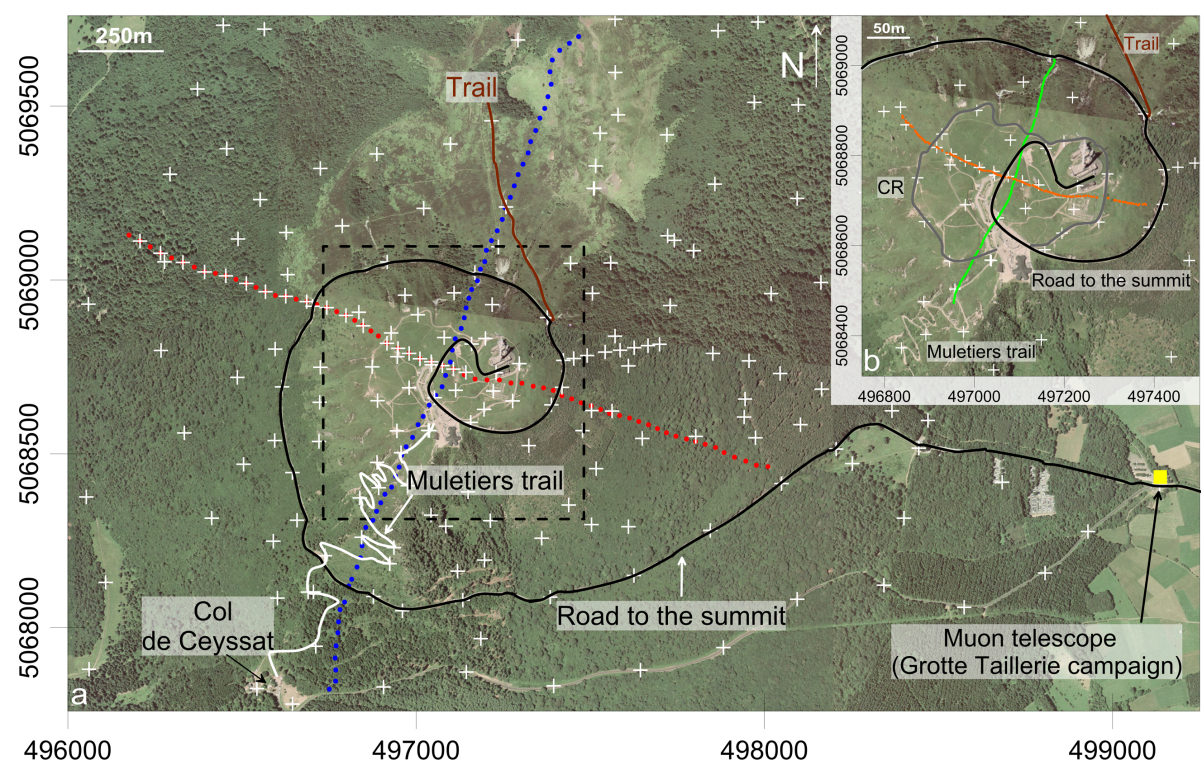

Fig. 2. Location of the ERT lines and gravimetric stations on the Puy de Dôme volcano (coordinates in meters WGS84, UTM31N). (a) ERT lines in N-S direction (blue dots) and E-W direction (red dots) are composed of 64 electrodes with 35 m electrode spacing; (b) ERT lines in the summit area (electrode spacing $5 \mathrm{~m}$ ) in N-S (green dots) and E-W (orange dots) directions. White crosses represent gravity stations. Yellow square refers to muon telescope position during the Grotte Taillerie campaign (January to July 2011).

The Res2Dinv software, developed by Loke and Barker (1996), was used to calculate 2-D models. Prior to inversion, data points can be visualized and edited. The data are plotted as pseudo-sections (a conventional presentation where the measured values are plotted at the centre of the quadripole, at the intersection of two $45^{\circ}$-dipping lines originating from current (i.e. outer) electrodes). For a given pseudo-depth, the values between adjacent points vary generally steadily. Sometimes, we can observe a value that departs abruptly from this trend. If the variation is unrealistically large, we can suspect a spurious measurement and we suppress the corresponding data. Bad points are usually due to poor electrode ground contact. In the Puy de Dôme case, 2 points out of 2225 were suppressed along the north-south profile and 23 points out of 2156 were suppressed along the west-east profile. The datasets along each profile comprise the data from both 35 and $5 \mathrm{~m}$ electrode spacing lines. The altitude of electrodes is taken into account in the sections provided by Res2Dinv model.

2-D resistivity models calculated with Res2Dinv have obvious limitations when a 3-D structure is suspected, but they have a proven ability to provide valuable information at the scale of a volcanic edifice (e.g. Finizola et al., 2006; Revil et al., 2004, 2008).

\subsection{High-resolution gravity survey}

The gravity survey method maps the gravity field variations induced by the uneven density distribution of the geological target. We have used a Scintrex CG-5 gravimeter that measures the relative gravity value difference between measurements stations. The absolute values of $g$ at the survey stations are computed using four reference stations of the New International Absolute Gravity Database (AGrav, Wilmes et al., 2009), available in (or close to) the area of our survey. In our survey, the station spacing (Fig. 2) was about $250 \mathrm{~m}$ in the distal zone (between 1 and $2 \mathrm{~km}$ from the summit) and $80 \mathrm{~m}$ in the proximal zone ( $1 \mathrm{~km}$ around the summit). Absolute gravity bases and secondary bases established during the survey were measured during each daily prospect. Typically, $50 \%$ of the station and base measurements were repeated twice during each prospect in order to have an optimum control on the quality of the data. The stations were localised using differential GPS measurements, and the resulting altimetry precision is better than $7 \mathrm{~cm}$.

For structural prospecting, the interpretation is usually based on the Bouguer anomaly that represents the difference between theoretical values for a homogeneous Earth and measured values. It is calculated from gravity data after several corrections are applied. The corrections are the following: instrumental and tide drift corrections, theoretical gravity value calculation (or latitude correction), free air correction, plateau correction (depending on density correction value $\rho_{\text {cor }}$ ) and topography correction (also with $\rho_{\text {cor }}$ ) (Chapin, 1996; LaFehr, 1991; Nowell, 1999; Telford et al., 1976). The topography correction was calculated using a high-resolution $50 \mathrm{~cm}$ DTM (Digital Terrain Model) with a vertical precision of $10 \mathrm{~cm}$. The resultant Bouguer anomaly, obtained with an accuracy estimated to $0.05 \mathrm{mGal}$, reflects the density variations in the ground (Portal, 2012). 

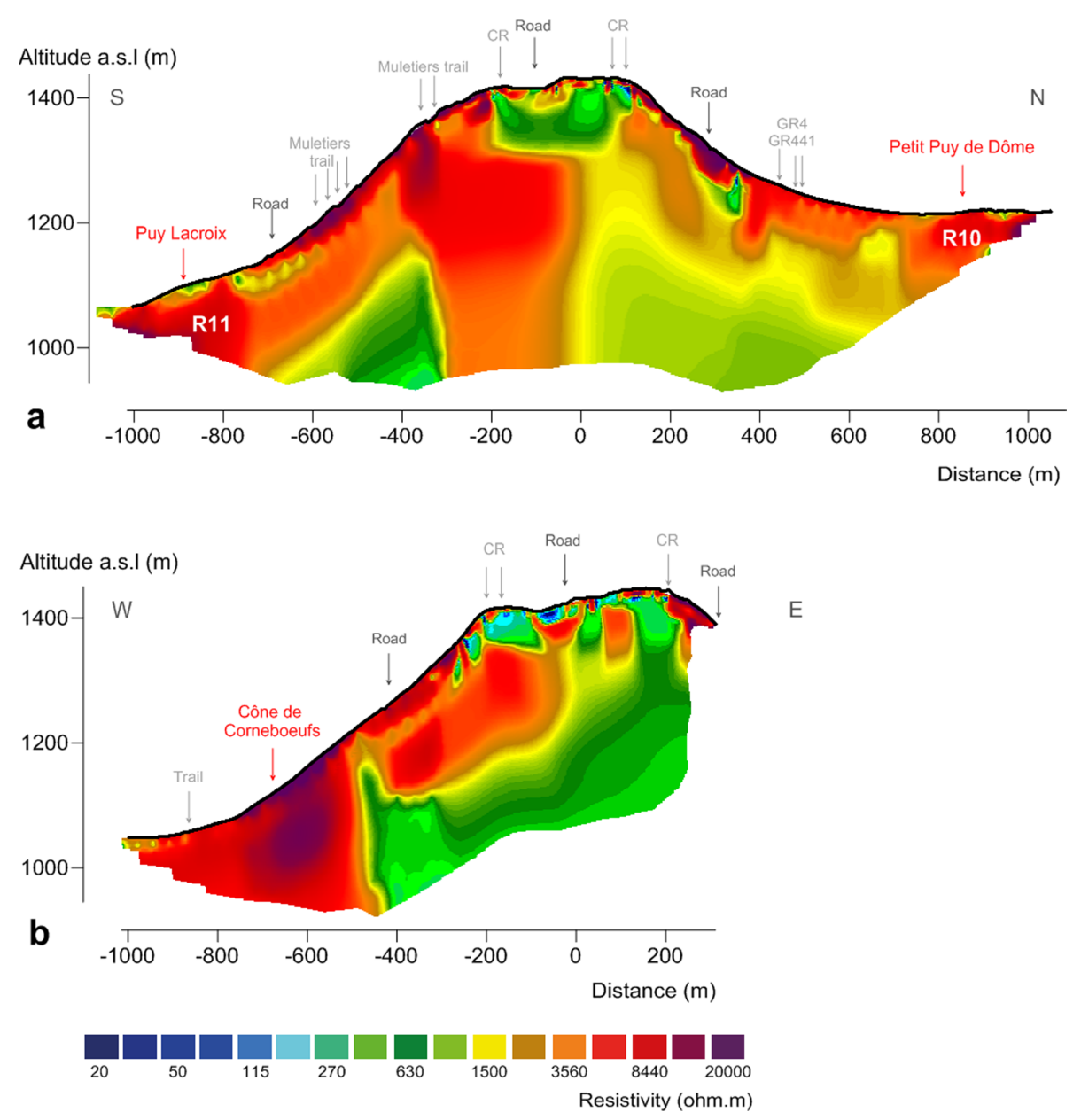

Fig. 3. 2-D resistivity models: (a) north-south direction; (b) west-east direction.

\section{Results}

\subsection{Resistivity distribution models of the Puy de Dôme volcano}

The two models shown in Fig. 3 have a rms error value of $7.4 \%$ for the north-south section and $16.9 \%$ for the eastwest model. The rms is calculated from the difference between the measured apparent resistivity and the apparent resistivity calculated for the model at each measurement point. Adding the data from the summit electrical survey, with $5 \mathrm{~m}$ electrode spacing, to the $35 \mathrm{~m}$ electrode spacing data, leads to a finer image of the superficial structures in the summit area.

The models show a general heterogeneity of the Puy de Dôme. Parts with resistivity higher than $5 \mathrm{k} \Omega \mathrm{m}$ suggest massive, unaltered or poorly altered rocks of the dome extrusion. Alternatively, they could also be low permeability, dry breccias or pyroclastics. Low resistivity parts $(\rho<1 \mathrm{k} \Omega \mathrm{m})$ can correspond to wet or intensely altered or brecciated rocks, or rocks containing conductive minerals (clay for example).
Superficial zones with high resistivity values are observed along the Puy de Dôme slopes. These formations have low thickness (tens of meters). Recent geological observations suggest that these structures could be lava flows emitted from a summit vent (D. Miallier and P. Boivin, personal communication, 2012).

In the periphery of the Puy de Dôme, high resistivity formations coincide with strombolian cones made of trachybasaltic scoriae (Petit Puy de Dôme, Puy Lacroix and Cône de Cornebœufs).

\subsection{Bouguer anomaly map}

The Bouguer anomaly is often correlated with the topography if the uniform density used for the topography correction is too different from the density of the rocks that create the topography. The Nettleton test determines the correction density that minimises the topography-anomaly correlation (Nettleton, 1939). In the case of the Puy de Dôme, the Nettleton test gives a correction density of $2.0 \times 10^{3} \mathrm{~kg} \mathrm{~m}^{-3}$. This density value corresponds to the averaged density at the 

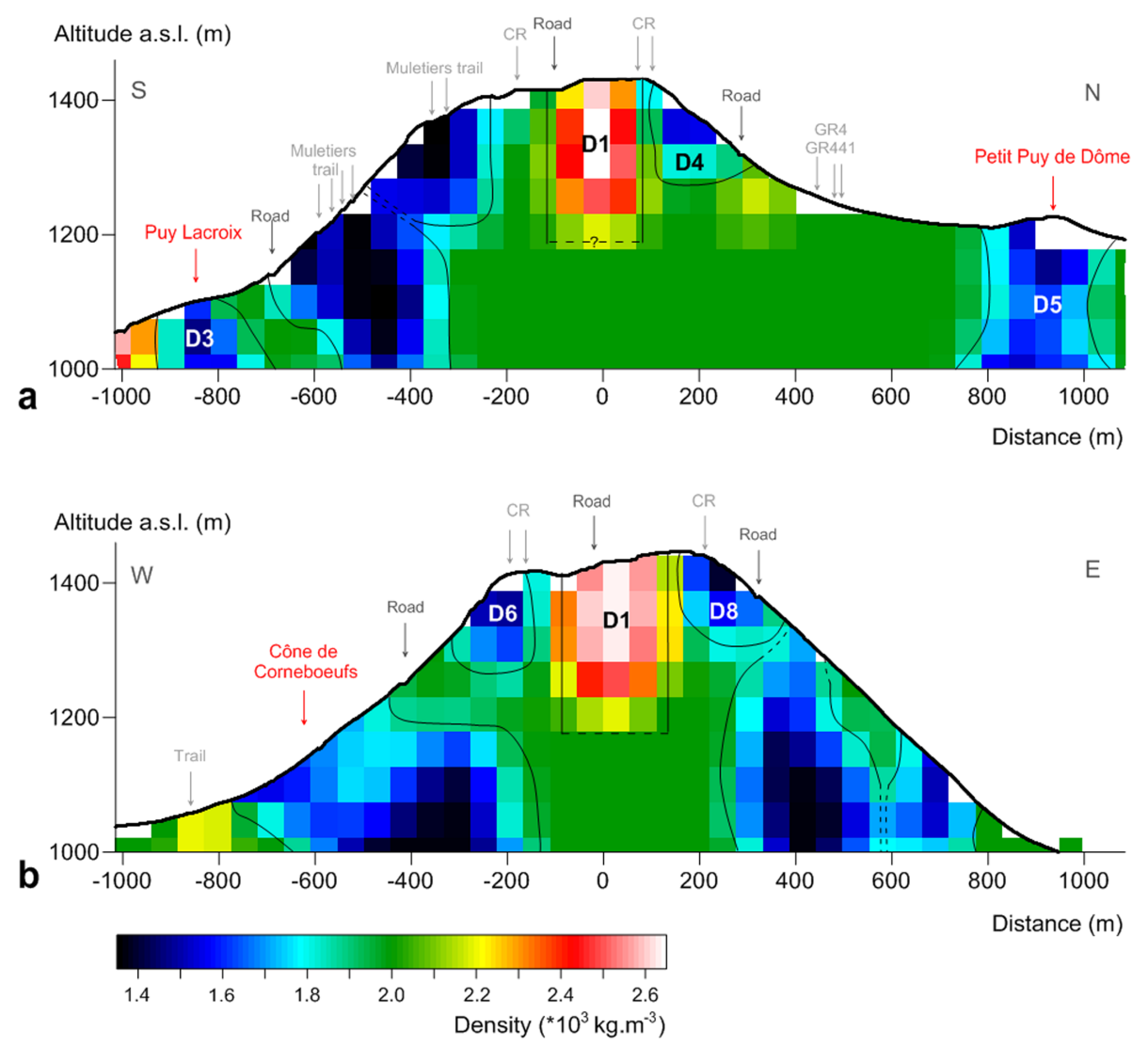

Fig. 4. Sections in the 3-D density models of the Puy de Dôme volcano.

volcano scale. This value is in good agreement with density measurements on samples of the Puy de Dôme rocks, which gave a range of $1.6-2.2 \times 10^{3} \mathrm{~kg} \mathrm{~m}^{-3}$.

The local anomaly was calculated by subtracting the regional component (first degree surface estimate). The resulting residual Bouguer anomaly with a density correction of $2.0 \times 10^{3} \mathrm{~kg} \mathrm{~m}^{-3}$ was used for the modelling.

The 3-D gravity models were obtained using an inversion package, GROWTH2.0, developed by Camacho et al. (2011). The range of density variation in the model has been fixed at $2.00 \pm 0.64 \times 10^{3} \mathrm{~kg} \mathrm{~m}^{-3}$ corresponding to standard values for trachytic domes and scoria cones. The rms inversion residual obtained for this model is better than $0.02 \mathrm{mGal}$.

Although this preliminary model still needs to be refined (for example by taking into account density measured on samples representative of the different types of rocks observed at the surface), it nevertheless provides a first order model of the density distribution within the dome. Figure 4 shows two 2-D sections extracted from the Puy de Dôme 3-D density model along the ERT profiles paths.

The dome construction is clearly heterogeneous in terms of density. A dense core is present under the summit area. In the present model, it extends down to about $200 \mathrm{~m}$ below the surface, but, as the reliability of the model decreases with depth, its lower boundary cannot be precisely determined without further constraints. This dense core is surrounded by lower-density structures visible in Fig. 4. Beneath the lower slopes of Puy de Dôme volcano, we observe formations with low-density values that are unambiguously associated in some areas with strombolian cones observed at the surface (Puy Lacroix, Petit Puy de Dôme, and Cône de Cornebœufs). These cones are mainly composed of low-density scoriaceous material. Only to the east, a low-density structure, very similar to those of the strombolian cones, cannot be formally attributed to a similar construction, because only products from the trachytic dome are present at the surface.

\section{Discussion}

\subsection{Comparison of resistivity and density models}

The comparison of the geophysical models inferred from electrical resistivity and gravity measurements along the north-south direction (Fig. 5a and b) shows both similar and different structures. Among the similar structures, the R10 and R11 high resistivity areas and the D5 and D3 low-density areas clearly match with two strombolian cones: the Petit Puy de Dôme at the north and the Puy Lacroix towards the south. Inside the dome, the correlation between resistivity 

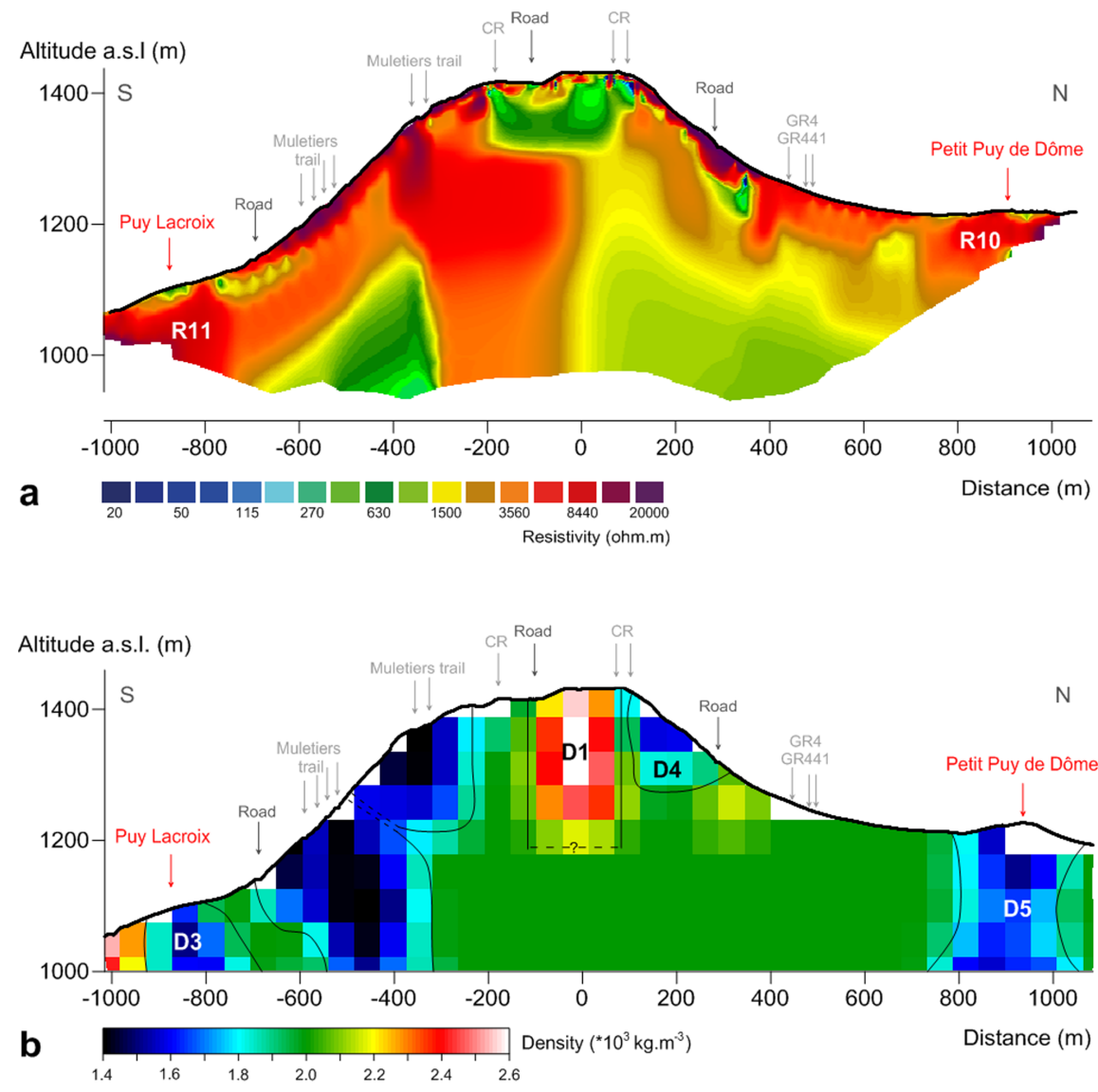

C

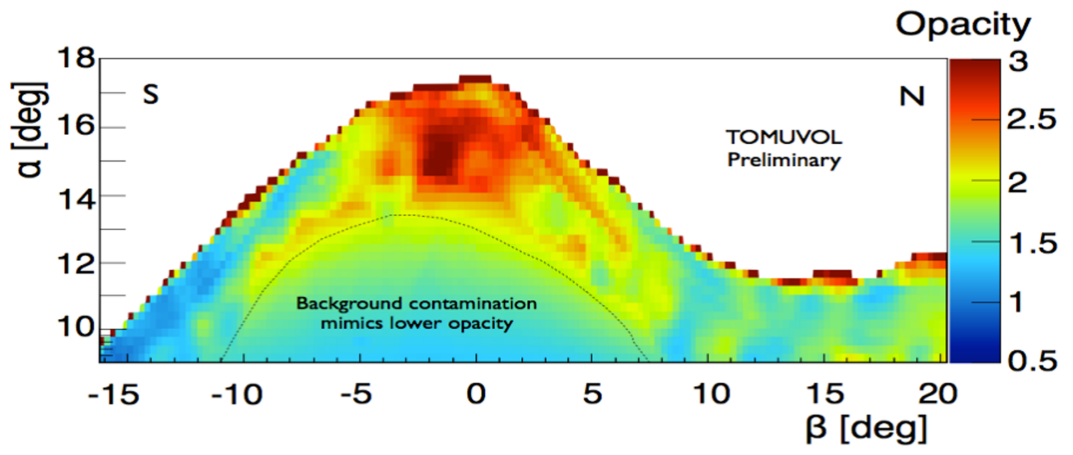

Fig. 5. Comparison of geophysical models along north-south direction: (a) 2-D resistivity model, (b) 3-D density model from gravimetry and (c) opacity model from muonic tomography (Cârloganu et al., 2012).

and density structures is not clear. Indeed, the dense D1 structure appearing in the gravimetry model has no resistivity equivalent as we would expect that massive intrusions would have both resistivity and density values higher than those of the other deposits such as pyroclastics and breccias. In the case of the Puy de Dôme volcano, the correlation between physical properties of rocks and their nature appears to be more complex.
Considering the geological nature of the Puy de Dôme, the dense central structure can be interpreted as a massive trachytic structure. However the variable resistivity of this structure can probably be linked to fracturing processes that facilitate the alteration of rocks by giving way to hydrologic and hydrothermal circulations. Obviously, the joint comparison of the resistivity and density structures has to be further investigated in the case of the Puy de Dôme. Rock sample study will help to understand the resistivity and density 
structures and will provide robust constraints to compute new geophysical models.

\subsection{Comparison of gravity and muon models}

Preliminary results for the Puy de Dôme opacity to atmospheric muons, measured in the Grotte Taillerie (radiography along the north-south section), are presented and discussed elsewhere (Cârloganu et al., 2012) Fig. 5c). This opacity is highly correlated to the integrated density along measurement viewpoints, though the muon radiography measurement is too preliminary to claim a density measurement using muons. Using Fig. 5 (b and c) we can attempt a first comparison of the preliminary results from the muon radiography with the density models obtained from gravity measurements.

The muon opacity image integrates the signal of muons crossing the dome along the west-east direction. Since muon attenuation is linearly linked with the rock density, comparisons with the gravity data can be attempted, keeping in mind that Fig. 5b represents a section in a 3-D model and Fig. 5c is linked to the integrated density across the dome. The dense margin along the topography profile is very likely an artefact due to the very low energy component of the atmospheric muon flux, which was not yet properly modelled and is dominant when measuring attenuation through small amounts of material.

The two models show a dense core located beneath the top of the volcano. This constitutes a strong validation for both methods. For the rest of the dome, where it is well investigated by the muon imaging (i.e. excluding the thick base of the dome where the muon signal is too small to be extracted from the contamination due to the atmospheric showers), more structures are observed. At this stage, we have not carried out a detailed analysis of these structures because of the preliminary nature of the muon radiography image results. However, it can be noted that even this preliminary image provides a good insight into expected accuracy of the muon imaging.

In the future, we intend to perform a joint inversion of the gravity and muon data to obtain better constrained models. This approach has already been applied by Nishiyama et al. (2012) for the Mt. Showa-Shinzan lava dome.

\section{Conclusions}

This study aims at comparing different geophysical models: ERT and gravity, on the one hand, and a comparison of these methods with muonic tomography on the other hand. Our goal is to develop a method to study the interior of volcanoes with muon tomography alone or with the addition of other conventional geophysical methods.

Our preliminary results on the Puy de Dôme volcano illustrate the complex correlation between different parameters.
Density and resistivity models are poorly correlated. Therefore further investigations, particularly on samples, are necessary to understand the differences between the density and resistivity structures of the dome. On the other hand, muon imaging and density models obtained by gravity data inversion are, as expected, better correlated.

Nevertheless the preliminary geophysical models provide new information on the Puy de Dôme inner structure and formation. In particular, they strongly suggest that the volcanic construction is not formed by the dome alone, but that this latter is erected inside a cluster of pre-existing large scoria cones. Study on the physical properties of the rocks of the Puy de Dôme is also necessary to better constrain our initial models. New geophysical measurements will also be carried out on the Puy de Dôme volcano to improve the existing dataset. The development of joint inversions is also considered in order to build models consistent with the different parameters.

Acknowledgements. This is Laboratory of Excellence ClerVolc contribution no. 48. The TOMUVOL collaboration acknowledges support from the Blaise Pascal University of Clermont-Ferrand, CNRS, Région Auvergne and Conseil Général du Puy-de-Dôme. The LIDAR data used in this study have been provided through a collective project driven by the Centre Régional Auvergnat de l'Information Géographique (CRAIG), which has been financially supported by the Conseil Général du Puy-de-Dôme, the Fonds Européen de développement Régional (FEDER) and the Blaise Pascal University of Clermont-Ferrand (UBP).

Edited by: E. P. Strolin

\section{References}

Alvarez, L. W., Anderson, J. A., Bedwei, F. E., Burkhar, J., Fakhry, A., Girgis, A., Goneid, A., Hassan, F., Iverson, D., and Lynch, G.: Search for hidden chambers in the pyramids, Science, 167 , 832-839, 1970.

Béné, S.: Air shower simulation for background estimation in muon tomography of volcanoes, Geosci. Instrum. Method. Data Syst. Discuss., 2, 563-574, doi:10.5194/gid-2-563-2012, 2012.

Boivin, P., Besson, J.-C., Briot, D., Camus, G., De Goër de Herve, A., Gourgaud, A., Labazuy, P., Langlois, E., De Larouzière, F.D., Livet, M., Mergoil, J., Miallier, D., Morel, J.-M., Vernet, G., and Vincent, P.: Volcanologie de la Chaîne des Puys, Parc Naturel Régional de la Chaîne des Puys, Carte et fascicule, 5th Edn., 200 pp., 2009.

Camacho, A. G., Fernández, J., and Gottsmann, J.: The 3D gravity inversion package GROWTH2.0 and its application to Tenerife Island, Spain, Comput. Geosci., 37, 621-633, doi:10.1016/j.cageo.2010.12.003, 2011.

Cârloganu, C., Niess, V., Béné, S., Busato, E., Dupieux, P., Fehr, F., Gay, P., Miallier, D., Vulpescu, B., Boivin, P., Combaret, C., Labazuy, P., Laktineh, I., Lénat, J.-F., Mirabito, L., and Portal, A.: Towards a muon radiography of the Puy de Dôme, Geosci. Instrum. Method. Data Syst. Discuss., 2, 765-780, doi:10.5194/gid-2-765-2012, 2012. 
Chapin, D. A.: The theory of the Bouguer gravity anomaly: A tutorial, Leading Edge, 15, 361-363, 1996.

Finizola, A., Revil, A., Rizzo, E., Piscitelli, S., Ricci, T., Morin, J., Angeletti, B., Mocochain, L., and Sortino, F.: Hydrogeological insights at Stromboli volcano (Italy) from geoelectrical, temperature, and $\mathrm{CO}_{2}$ soil degassing investigations, Geophys. Res. Lett., 33, L17304, doi:10.1029/2006GL026842, 2006.

Gibert, D., Beauducel, F., Déclais, Y., Lesparre, N., Marteau, J., Nicollin, F., and Tarantola, A.: Muon tomography: Plans for observations in the Lesser Antilles, Earth Planet. Space, 62, 153165, doi:10.5047/eps.2009.07.003, 2010.

LaFehr, T. R.: Standardization in gravity reduction, Geophysics, 56, 1170-1178, 1991.

Lesparre, N., Gibert, D., Marteau, J., Komorowski, J.-C., Nicollin, F., and Coutant, O.: Density muon radiography of La Soufrière of Guadeloupe volcano: comparison with geological, electrical resistivity and gravity data, Geophys. J. Int., 190, 1008-1019, doi:10.1111/j.1365-246X.2012.05546.x, 2012.

Loke, M. H. and Barker, R. D.: Practical techniques for 3D resistivity surveys and data inversion, Geophys. Prospect., 44, 499-523, 1996.

Marescot, L.: Modélisation directe et inverse en prospection électrique sur des structures 3D complexes par la méthode des éléments finis, Université de Nantes et Université de Lausanne, 208 pp., 2004.

Marteau, J., Gibert, D., Lesparre, N., Nicollin, F., Noli, P., and Giacoppo, F.: Muons tomography applied to geosciences and volcanology, Nuclear Instruments and Methods in Physics Research Section A: Accelerators, Spectrometers, Detect. Associat. Equip., 695, 23-28, doi:10.1016/j.nima.2011.11.061, 2012.

Miallier, D., Boivin, P., Deniel, C., Gourgaud, A., Lanos, P., Sforna, M., and Pilleyre, T.: The ultimate summit eruption of Puy de Dôme volcano (Chaîne des Puys, French Massif Central) about 10,700 years ago, Comptes Rendus Geoscience, 342, 847-854, doi:10.1016/j.crte.2010.09.004, 2010.

Nagamine, K.: Geo-tomographic observation of inner structure of volcano with cosmic-ray muons, J. Geography, 104, 998-1007, 1995.

Nagamine, K., Iwasaki, M., Shimomura, K., and Ishida, K.: Method of probing inner-structure of geophysical substance with the horizontal cosmic-ray muons and possible application to volcanic eruption prediction, Nucl. Instrum. Meth. Phys. Res. A, 56, 585595,1995

Nettleton, L. L.: Determination of density for reduction of gravimeter observations, Geophysics, 4, 176-183, 1939.

Nishiyama, H., Oshima, H., Maekawa, T., Tanaka, Y., and Okubo, S.: Development of a joint inversion technique using gravity and muon-radiographic data for resolving three-dimensional density structure of a gigantic body, in High energy geophysics: Muon and Neutrino Radiography, Geosci. Instrum. Method. Data Syst. Discuss., in preparation, 2012.

Nowell, D. A. G.: Gravity terrain corrections - an overview, J. Appl. Geophys., 42, 117-134, 1999.

Portal, A.: Apports des méthodes géophysiques (résistivités électriques, gravimétrie) dans l'étude des édifices volcaniques et comparaison avec la tomographie muonique?: exemple du Puy de Dôme, Master Report, Université Blaise Pascal, ClermontFerrand, 50 pp., 2012.
Revil, A., Finizola, A., Sortino, F., and Ripepe, M.: Geophysical investigations at Stromboli volcano, Italy: implications for ground water flow and paroxysmal activity, Geophys. J. Int., 157, 426440, doi:10.1111/j.1365-246X.2004.02181.x, 2004.

Revil, A., Finizola, A., Piscitelli, S., Rizzo, E., Ricci, T., Crespy, A., Angeletti, B., Balasco, M., Barde Cabusson, S., Bennati, L., Bolève, A., Byrdina, S., Carzaniga, N., Di Gangi, F., Morin, J., Perrone, A., Rossi, M., Roulleau, E., and Suski, B.: Inner structure of La Fossa di Vulcano (Vulcano Island, southern Tyrrhenian Sea, Italy) revealed by high-resolution electric resistivity tomography coupled with self-potential, temperature, and $\mathrm{CO}_{2}$ diffuse degassing measurements, J. Geophys. Res., 113, B07207, doi:10.1029/2007JB005394, 2008.

Tanaka, H. K. M. and Yokoyama, I.: Muon radiography and deformation analysis of the lava dome formed by the 1944 eruption of Usu, Hokkaido - Contact between high-energy physics and volcano physics, Proc. Japan Acad. Ser. B, 84, 107-116, 2008.

Tanaka, H. K. M., Nagamine, K., Nakamura, S. N., and Ishida, K.: Radiographic measurements of the internal structure of Mt. West Iwate with near-horizontal cosmic-ray muons and future developments, Nuclear Instruments and Methods in Physics Research Section A: Accelerators, Spectrometers, Detect. Associat. Equip., 555, 164-172, doi:10.1016/j.nima.2005.08.099, 2005.

Tanaka, H., Nakano, T., Takahashi, S., Yoshida, J., Takeo, M., Oikawa, J., Ohminato, T., Aoki, Y., Koyama, E., and Tsuji, H.: High resolution imaging in the inhomogeneous crust with cosmic-ray muon radiography: The density structure below the volcanic crater floor of Mt. Asama, Japan, Earth Planet. Sc. Lett., 263, 104-113, doi:10.1016/j.epsl.2007.09.001, 2007.

Tanaka, H. K. M., Uchida, T., Tanaka, M., Shinohara, H., and Taira, H.: Cosmic-ray muon imaging of magma in a conduit: Degassing process of Satsuma-Iwojima Volcano, Japan, Geophys Res. Lett., 36, 1-5, doi:10.1029/2008GL036451, 2009a.

Tanaka, H. K. M., Uchida, T., Tanaka, M., Takeo, M., Oikawa, J., Ohminato, T., Aoki, Y., Koyama, E., and Tsuji, H.: Detecting a mass change inside a volcano by cosmic-ray muon radiography (muography): First results from measurements at Asama volcano, Japan, Geophys. Res. Lett., 36, L17302, doi:10.1029/2009GL039448, 2009b.

Tanaka, H. K. M., Taira, H., Uchida, T., Tanaka, M., Takeo, M., Ohminato, T., Aoki, Y., Nishitama, R., Shoji, D., and Tsuiji, H.: Three-dimensional computational axial tomography scan of a volcano with cosmic ray muon radiography, J. Geophys. Res., 115, B12332, doi:10.1029/2010JB007677, 2010.

Telford, W. M., Geldart, L. P., Sheriff, R. E. and Keys, D. A.: Applied Geophysics, Cambridge University Press, London, Cambridge, 770 pp., 1976.

White, R. M. S., Collins, S., and Loke, M. H.: Resistivity and IP arrays, optimised for data collection and inversion, Explor. Geophys., 34, 229-232, 2003.

Wilmes, H., Wziontek, H., Falk, R., and Bonvalot, S.: AGrav - The New International Absolute Gravity Database of BGI and BKG and its benefit for the Global Geodynamics Project (GGP), J Geodynam., 48, 305-309, doi:10.1016/j.jog.2009.09.035, 2009. 